\title{
Transactivation of PDGFR $\beta$ by dopamine D4 receptor does not require PDGFR $\beta$ dimerization
}

Sum Shing $\mathrm{Chi}^{1 \dagger}$, Sandra M Vetiska ${ }^{1 \dagger}$, Robin S Gill${ }^{2}$, Marilyn S Hsiung ${ }^{2}$, Fang Liu ${ }^{1,3^{*}}$, Hubert HM Van Tol ${ }^{1,2,3}$

\begin{abstract}
Growth factor-induced receptor dimerization and cross-phosphorylation are hallmarks of signal transduction via receptor tyrosine kinases (RTKs). G protein-coupled receptors (GPCRs) can activate RTKs through a process known as transactivation. The prototypical model of RTK transactivation involves ligand-mediated RTK dimerization and cross-phosphorylation. Here, we show that the platelet-derived growth factor receptor $\beta$ (PDGFR $\beta$ ) transactivation by the dopamine receptor D4 (DRD4) is not dependent on ligands for PDGFR $\beta$. Furthermore, when PDGFR $\beta$ dimerization is inhibited and receptor phosphorylation is suppressed to near basal levels, the receptor maintains its ability to be transactivated and is still effective in signaling to ERK1/2. Hence, the DRD4-PDGFR 3 -ERK1/2 pathway can occur independently of a PDGF-like ligand, PDGFR $\beta$ cross-phosphorylation and dimerization, which is distinct from other known forms of transactivation of RTKs by GPCRs.
\end{abstract}

\section{Introduction}

Receptor tyrosine kinases (RTKs) consist of a large family of receptors whose members serve a wide range of physiological functions including growth, differentiation and synaptic modulation. The members of this receptor family generally feature an extracellular ligandbinding domain, linked by a transmembrane domain to an intracellular tyrosine kinase domain, as well as several SH2 domain-binding sites. It is generally believed that the mechanism of RTK signaling involves ligandinduced dimerization of the RTK followed by crossphosphorylation of the tyrosine-containing motifs, which subsequently interact with $\mathrm{SH} 2$ domain-containing molecules such as the PI3-kinase, PLC- $\gamma$, Src, SHP-2, Grb-2 and RasGAP, to effect downstream responses [1].

The large family of $G$ protein-coupled receptors (GPCRs) activates heterotrimeric $\mathrm{G}$ proteins and can mediate several cellular processes, including proliferation, differentiation and survival. The ERK $1 / 2$ signaling pathway is among the major effector pathways through which GPCRs mediate their responses [2,3]. Many GPCRs engage in ERK1/2 signaling via the activation of RTKs, in a process known as transactivation [2-4]. GPCRs such as the dopamine receptors D4 (DRD4) and

\footnotetext{
* Correspondence: fang_liu@camh.net

† Contributed equally

${ }^{1}$ Department of Neuroscience, Centre for Addiction and Mental Health, University of Toronto, Toronto, M5T 1R8, Canada
}

D2 (DRD2) [5-7], $\beta_{2}$ adrenergic receptor [8], $\mathrm{M}_{1}$ muscarinic receptor [9], angiotensin II receptor [10], lysophosphatidic acid (LPA) receptor [11], ET1 receptor [12] and thrombin receptor [12] have been shown to transactivate either the epidermal growth factor receptor (EGFR) or the platelet-derived growth factor receptor $\beta$ (PDGFR $\beta$ ). Upon GPCR stimulation, these transactivated RTKs exhibit increased tyrosine phosphorylation, as seen similarly following growth factor-induced activation. The transactivation of EGFR by the $\beta_{2}$ adrenergic receptor is also characterized by increased dimerization of EGFR [8]. In many cases, the transactivation of EGFR is mediated in either a paracrine or autocrine fashion by the metalloproteinase-dependent release of heparinbinding (HB)-EGF. Hence, the mechanism of EGFR activation by GPCRs is similar to that by its own ligand.

Previous work from our laboratory and our collaborators has demonstrated the DRD4-mediated transactivation of PDGFR $\beta$ in hippocampal neurons [13] as well as in DRD4-expressing CHO-K1 cells [5]. Despite speculation of a similar mechanism to EGFR transactivation, the mechanism of PDGFR $\beta$ transactivation is not clear. The present study aims to investigate the mechanism by which the PDGFR $\beta$ is transactivated via DRD4 by examining the roles of a paracrine or autocrine mediator, PDGFR $\beta$ cross-phosphorylation and PDGFR $\beta$ dimerization in this process. 


\section{Experimental Procedures Reagents and antibodies}

Recombinant human PDGF-BB was purchased from R\&D Systems (Minneapolis, MN, USA). Dopamine, wortmannin and tyrphostin A9 were obtained from Sigma-RBI (St. Louis, MO, USA). AG1295 and GM6001 were purchased from Calbiochem (San Diego, CA, USA). CRM197 was purchased from List Biochemical Laboratories (Campbell, CA, USA). Antibodies raised against $\beta$-tubulin, phospho-Shc and the carboxy terminal region of human PDGFR $\beta$ from residues 958 to 1106 were obtained from Santa Cruz Biotechnology (Santa Cruz, CA, USA). Antibodies raised against the extracellular domain of human PDGFR $\beta$ were obtained in a biotinylated form from R\&D Systems (Minneapolis, MN, USA). Antibodies specific to different phosphorylation sites on PDGFR $\beta$ were obtained from two different sources. Anti-phospho-PDGFR $\beta$-Tyr716 was from Upstate Biotechnology (Charlottesville, VA, USA), and phosphospecific PDGFR $\beta$ antibodies directed against Tyr740, 751, 857, and 1021 were purchased from Santa Cruz Biotechnology (Santa Cruz, CA, USA). General phosphotyrosine antibodies in an unconjugated form (4G10) and in a horseradish peroxidase-conjugated form (PY20) were purchased from Upstate Biotechnology (Charlottesville, VA, USA) and BD Transduction Laboratories (Franklin Lakes, NJ, USA), respectively. Antibodies to ERK1/2 and phospho-ERK1/2 (Thr202/ Tyr204) (E10) were obtained from Cell Signaling Technology (Beverly, MA, USA). Anti-FLAG antibody was purchased from Sigma (St. Louis, MO, USA). Peroxidase-conjugated antibodies to mouse and rabbit IgG were purchased from Sigma (St. Louis, MO, USA) and Cell Signaling Technology (Beverly, MA, USA), respectively. Lipofectamine, G418, zeocin, fetal bovine serum, and horse serum were purchased from Invitrogen Life Technologies (Burlington, ON, Canada). Media used in cell cultures were obtained from either Invitrogen Life Technologies (Burlington, ON, Canada) or Sigma (St. Louis, MO, USA).

\section{Plasmids}

Expression vectors for epitope-tagged DRD4 and PDGFR $\beta$ have been described by us previously [5]. The plasmid encoding the FLAG-tagged human PDGFR $\beta$ was a gift from Dr. N. J. Freedman (Duke University, NC, USA) [14]. All plasmids were subcloned into either pcDNA3 or pcDNA3.1 vectors (Invitrogen) containing antibiotic resistance genes for selection with either G418 or zeocin, respectively. A carboxyl-terminal truncated human PDGFR $\beta$ (C-truncPDGFR $\beta$ ) was constructed, as reported by Ueno et al. [15] for the mouse PDGFR $\beta$, by truncating the wild-type human receptor after amino acid residue 615 [16]. The insert coding for this truncated receptor was cloned into the EcoRI and $X b a \mathrm{I}$ restriction endonuclease sites in pcDNA3.1-Myc-His-A vector (Invitrogen) for C-terminal tagging of the protein and expression in mammalian cells. To construct the GST-Ig $4 \beta$, the fourth immunoglobulin domain of the mouse PDGFR $\beta$ was taken as the region from amino acid residues 314 to 413 [16], based on an alignment with the region reported for the human receptor [17], and cloned into the BamHI and EcoRI restriction endonuclease sites in pGEX-3X (Amersham, Little Chalfont, Buckinghamshire, UK). The sequences of the inserts in all the plasmids used in the present study were confirmed by automatic sequencing (CEQ 2000XL, Beckman Coulter).

\section{Cell cultures and transfection}

$\mathrm{CHO}-\mathrm{K} 1$ cells were maintained in $\alpha$-MEM supplemented with $2.5 \%$ fetal bovine serum and $2.5 \%$ horse serum [5]. CHO-K1 cells stably expressing HA-DRD4 (CHO/ DRD4) or FLAG-PDGFR $\beta$ (CHO/PR) alone were maintained in the serum-containing medium supplemented

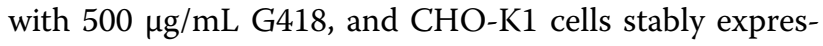
sing both the HA-DRD4 and FLAG-PDGFR $\beta$ (CHO/ DRD4-PR) were maintained in serum-containing medium supplemented with both $500 \mu \mathrm{g} / \mathrm{mL}$ G418 and 200 $\mu \mathrm{g} / \mathrm{mL}$ zeocin.

For assays on cell lines not subject to further transfection, the cells were seeded and grown to $70-90 \%$ confluency prior to serum-deprivation. Transfection was performed on $100 \mathrm{~mm}$ plates with a mixture containing $36 \mu \mathrm{L}$ lipofectamine and $8 \mu \mathrm{g}$ DNA. The mixture was prepared in $0.6 \mathrm{~mL}$ OPTI-MEM (Invitrogen) and incubated for 45 minutes at room temperature before another $6.4 \mathrm{~mL}$ of OPTI-MEM was added to yield the final transfection mixture. One day prior to transfection, cells were seeded at a density of $2 \times 10^{6}$ cells per 100 $\mathrm{mm}$. Transfection was allowed to take place for $5 \mathrm{~h}$, after which time an equal volume of $2 \times$ serum-containing $\alpha$-MEM was added. On the following day, cells intended for assays were replated at $60-80 \%$ confluency or at $0.4-1 \%$ for establishing stable cell lines. To establish cell lines expressing the desired constructs stably, the transfected cells were allowed to form isolated colonies. Positive colonies were selected by their resistance to G418 or zeocin. The expression of the desired proteins in the isolated colonies was determined by western blotting.

\section{SiRNA}

The two double-stranded RNA constructs containing the PDGFR $\beta$-specific sequences used were PDGFR $\beta$ silencer 1: (sense) 5'-GCAUCUUCAACAGCCUCUAtt$3^{\prime}$ and (antisense) 5'-CAGAGGCUGUUGAAGAUGCtt$3^{\prime}$ and PDGFR $\beta$ silencer 2: (sense) 5'-GUGGACUCCGAUACUUACUtt-3' and (antisense) 5'-AGUAAGUAUCGGAGUCCACtt-3'. These oligonucleotides, as well as the scrambled siRNA (cat. \# 4611), were 
purchased from Ambion (Austin, TX). To suppress PDGFR $\beta$ expression, $\mathrm{CHO} / \mathrm{DRD} 4$ cells were transfected with 30 or $100 \mathrm{nM}$ dsRNA using siPORT transfection reagent (Ambion, Austin, TX) according to the manufacturer's instructions. After $72 \mathrm{~h}$, the cells were used for pharmacological manipulation and harvested for western analysis.

\section{GST-Ig4 fusion protein blocking experiments}

GST and GST-Ig $4 \beta$ fusion proteins were expressed in BL21 E. coli. Purification from bacterial lysates was carried out according to the manufacturer's protocol (Amersham). Elution from glutathione-Sepharose beads (Amersham) was performed as described by Omura et al. [18]. For cell assays, the purified proteins were applied at $4 \mu \mathrm{g} / \mathrm{mL}$ and pre-incubated for 20 minutes at $37^{\circ} \mathrm{C}$ prior to agonist stimulation.

\section{Cell assays}

CHO-K1 cells were serum-deprived for $24 \mathrm{~h}$ prior to assays with either PDGF-BB $(10 \mathrm{ng} / \mathrm{mL})$ or dopamine (1 $\mu \mathrm{M})$ for 5 minutes. In experiments using kinase inhibitors, the cells were pre-incubated with the inhibitor or the appropriate vehicle control solution for $1 \mathrm{~h}$ before stimulation with the agonists. Following incubation, cells were chilled immediately on ice and washed two times with ice-cold PBS (137 mM NaCl, $2.7 \mathrm{mM} \mathrm{KCl}, 5.4 \mathrm{mM}$ $\mathrm{Na}_{2} \mathrm{HPO}_{4}, 1.8 \mathrm{mM} \mathrm{KH} \mathrm{PO}_{4}$, pH 7.4). Cells were scraped on ice in RIPA buffer supplemented with protease and phosphatase inhibitors ( $50 \mathrm{mM}$ Tris- $\mathrm{HCl}, \mathrm{pH} 7.5,150$ $\mathrm{mM} \mathrm{NaCl}, 1 \mathrm{mM}$ EDTA, $1 \mathrm{mM}$ EGTA, 1\% NP-40, 0.5\% deoxycholate, $0.1 \%$ SDS, $5 \mu \mathrm{g} / \mathrm{mL}$ aprotinin, $2 \mu \mathrm{g} / \mathrm{mL}$ leupeptin, $1 \mu \mathrm{g} / \mathrm{mL}$ pepstatin A, $1 \mathrm{mM}$ PMSF, $1 \mathrm{mM}$ $\mathrm{Na}_{3} \mathrm{VO}_{4}, 2.5 \mathrm{mM}$ pyrophosphate. $\mathrm{Na}, 1 \mathrm{mM} \beta$-glycerophosphate). Sodium orthovanadate was activated using the method described by Gordon et al. [19]. Lysis was performed at $4^{\circ} \mathrm{C}$ for $1 \mathrm{~h}$ with continuous shaking. An equal amount of protein was taken from each sample for further analysis by immunoprecipitation and/or western blotting.

\section{Immunoprecipitation and immunoblotting}

Immunoprecipitation was performed by mixing 1-2 $\mu \mathrm{g}$ antibody with RIPA cell lysates. The mixture was shaken for a minimum of $1 \mathrm{~h}$ to overnight at $4^{\circ} \mathrm{C}$. After addition of $25 \mu \mathrm{L}$ Protein A/G Plus beads (Santa Cruz), the incubation was allowed to continue for a total of 17-19 $\mathrm{h}$ at $4^{\circ} \mathrm{C}$. Immunoprecipitates were collected by centrifugation after washing three times with the NP-40 buffer (50 mM HEPES, $250 \mathrm{mM} \mathrm{NaCl}, 0.5 \%$ NP-40, 10\% glycerol, $2 \mu \mathrm{mM}$ EGTA, $5 \mu \mathrm{g} / \mathrm{mL}$ aprotinin, $2 \mu \mathrm{g} / \mathrm{mL}$ leupeptin, $1 \mu \mathrm{g} / \mathrm{mL}$ pepstatin A, $1 \mathrm{mM}$ PMSF, $1 \mathrm{mM}$ $\mathrm{Na}_{3} \mathrm{VO}_{4}, 2.5 \mathrm{mM}$ pyrophosphate-Na, $1 \mathrm{mM} \beta$ glycerophosphate).

Immunoblotting with phosphotyrosine antibody was performed with a procedure adapted from Klapper et al. $[20]$ to reduce background staining. Briefly, the blocking of non-specific binding on PVDF membranes and the dilution of antibodies was performed in blocking buffer A $(10 \mathrm{mM}$ Tris- $\mathrm{HCl}, 154 \mathrm{mM} \mathrm{NaCl}, 2.5 \mathrm{mM} \mathrm{MgCl}, 3 \%$ BSA, pH 7.4). Following incubation with antibodies, the membranes were washed twice with the buffer $\mathrm{B}$ (10 $\mathrm{mM}$ Tris- $\mathrm{HCl}, 0.9 \% \mathrm{NaCl}, 0.05 \% \mathrm{MgCl}_{2}, \mathrm{pH} 7.4$ ), once with blocking buffer B supplemented with $0.3 \%$ Tween 20 , and twice more with the blocking buffer B. Each wash was carried out for 5 minutes on a rocking platform. Blocking buffer C (10 mM Tris- $\mathrm{HCl}, 150 \mathrm{mM}$ $\mathrm{NaCl}, 3 \% \mathrm{BSA}, 0.1 \%$ Tween 20, $\mathrm{pH}$ 7.4) was used in all associated procedures for immunoblotting with biotinylated antibodies, and blotto $(10 \mathrm{mM}$ Tris- $\mathrm{HCl}, 150 \mathrm{mM}$ $\mathrm{NaCl}, 5 \%$ non-fat dry milk, $0.1 \%$ Tween 20 , pH 7.4) was used for immunoblotting with other antibodies. Working dilutions of antibodies were prepared as recommended by manufacturers.

\section{Data Analysis}

Densitometry was performed on Storm 860 phosphorimager (Amersham) with ECL Plus chemiluminescent reagent (Amersham). Quantitation was done using ImageQuant 5.0 software (Molecular Dynamics). Curve fitting was performed in GraphPad Prism 3.0 (San Diego, CA, USA). Details pertaining to specific experiments are provided in the legends to the figures.

\section{Results}

Growth factor-activated PDGFR $\beta$ results in receptor cross-phosphorylation of tyrosine residues. We have previously shown that, in CHO-K1 cells stably expressing DRD4 (CHO/DRD4), dopamine stimulates the phosphorylation of ERK1/2 in a manner sensitive to the inhibition of the PDGFR $\beta$ kinase [5]. Therefore, we initiated our study by examining whether dopamine and the PDGFR $\beta$ ligand, PDGF-BB, activate the PDGFR $\beta$ in a similar manner. The commercially available antibodies do not reliably detect the phosphorylation of the endogenously expressed hamster PDGFR $\beta$ in the $\mathrm{CHO} /$ DRD4 cells; therefore, to facilitate the detection of PDGFR $\beta$ phosphorylation at the different tyrosine phosphorylation sites, the human FLAG-tagged PDGFR $\beta$ was stably transfected into the CHO/DRD4 cells to create CHO/DRD4-PR cells [14]. In CHO/DRD4-PR cells, the DRD4-mediated PDGFR $\beta$ and ERK1/2 phosphorylation was inhibited by pre-treatment with the PDGFR $\beta$ kinase inhibitors, tyrphostin A9, AG1295, and AG1296 in a similar manner as in the CHO/DRD4 cells (data not shown).

Using the CHO/DRD4-PR cells, we compared the pattern of PDGFR $\beta$ phosphorylation after stimulation with either $1 \mu \mathrm{M}$ dopamine or $10 \mathrm{ng} / \mathrm{mL}$ PDGF-BB. As shown in Figure 1A, the level of total tyrosine phosphorylation of PDGFR $\beta$ was less following dopamine treatment compared to PDGF-BB stimulation. 


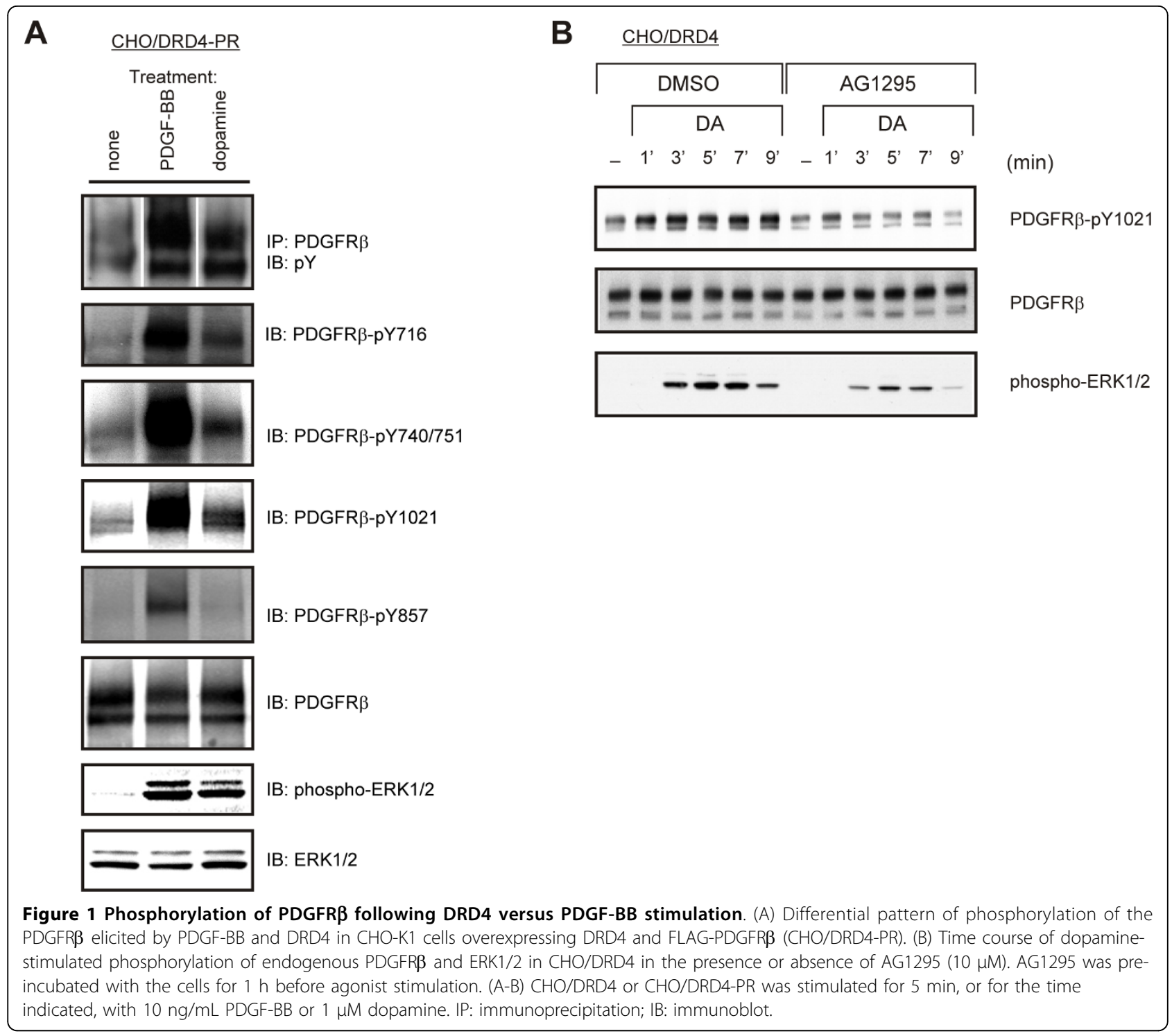

Consistently, using site-specific phospho-antibodies, several SH2 domain-binding sites [Grb2 (Tyr716), PI3kinase (Tyr740/751) and PLC- $\gamma$ (Tyr1021)] of the PDGFR $\beta$ also showed stronger phosphorylation in response to PDGF-BB compared to dopamine. Interestingly, Tyr857, the major site of tyrosine phosphorylation in PDGF-stimulated cells [21], was phosphorylated only by PDGF-BB, but not dopamine (Figure 1A). The absence of phosphorylation of this site may explain the overall lower tyrosine phosphorylation of PDGFR $\beta$ caused by DRD4 stimulation.

Since the receptor kinase activity is not enhanced through Tyr857 phosphorylation, the dopamine-induced PDGFR $\beta$ phosphorylation may be a result of the basal kinase activity of the PDGFR $\beta$. The phospho-specific antibody against Tyr1021 of the PDGFR $\beta$ does recognize the endogenously expressed hamster receptor; therefore, we used this antibody to measure PDGFR $\beta$ phosphorylation in CHO/DRD4 cells. As shown in Figure $1 \mathrm{~B}$, the dopamine-induced tyrosine phosphorylation of PDGFR $\beta$ (Tyr1021) and the phosphorylation of ERK1/2 were reduced by the PDGFR $\beta$ kinase inhibitor AG1295.

To provide direct evidence for a role of the PDGFR $\beta$ in dopamine-stimulated ERK1/2 activation, we used siRNA to suppress endogenous PDGFR $\beta$ expression in the CHO/DRD4 cells. In these cells, the PDGFR $\beta$ exists as two isoforms that can be detected by western blotting: a maturely glycosylated receptor $(180 \mathrm{kDa})$ and a $140 \mathrm{kDa}$, immaturely glycosylated, isoform [22,23]. In our siRNA experiments, two separate dsRNA constructs were used that showed a similar efficacy in reducing the levels of maturely glycosylated PDGFR $\beta$ (Figure 2A, B). 

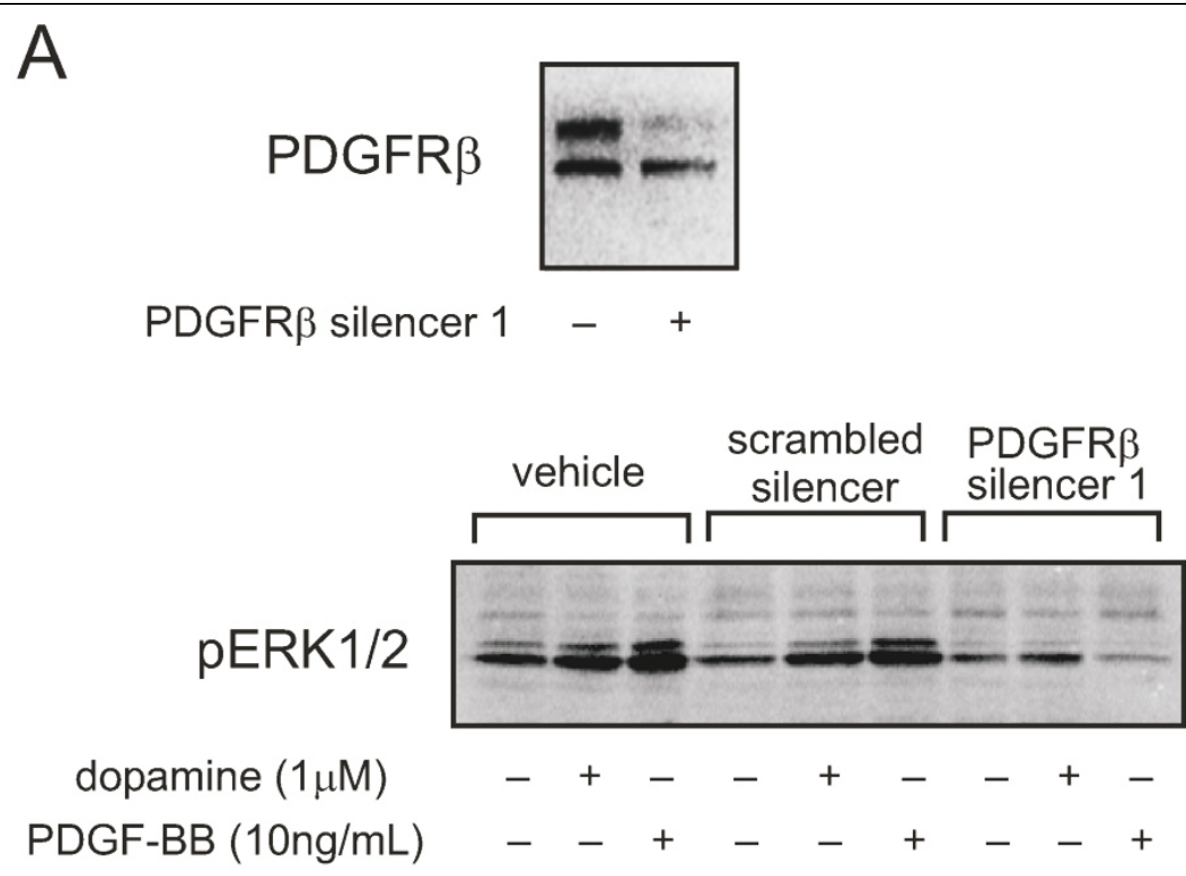

B
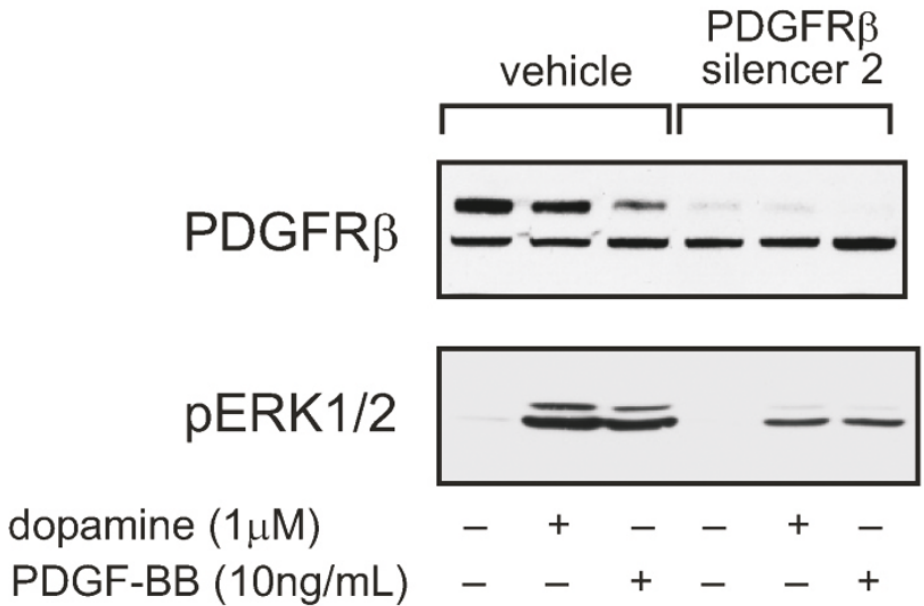

Figure 2 PDGFR $\beta$ siRNAs inhibit dopamine-mediated ERK1/2 activation. (A) $100 \mathrm{nM}$ of double-stranded PDGFR $\beta$ interference RNA (PDGFR $\beta$ silencer 1) or (B) $30 \mathrm{nM}$ of double-stranded PDGFRß RNA (PDGFRß silencer 2) was transfected into the CHO/DRD4 cells. Cells were harvested at $72 \mathrm{~h}$ post transfection and PDGFR $\beta$ expression was determined. For phospho-ERK1/2 expression (Thr202/Tyr204), cells were serum-starved overnight (beginning at $48 \mathrm{~h}$ post-transfection) and subsequently treated with dopamine (1 $\beta \mathrm{M})$ or PDGF-BB $(10 \mathrm{ng} / \mathrm{ml})$.

We observed that the $140 \mathrm{kDa}$ immaturely glycosylated form of PDGFR $\beta$ was not effectively suppressed by either siRNA approach. This band was still present in our western blots when different PDGFR $\beta$ antibodies were used; additionally, a similar band was seen in
CHO/DRD4 cells transfected with FLAG epitope-tagged PDGFR $\beta$ (not shown), suggesting that this band represents a genuine isoform of PDGFR $\beta$. Upon siRNAmediated PDGFR $\beta$ suppression, both dopamine $(1 \mu \mathrm{M})$ and PDGF-BB $(10 \mathrm{ng} / \mathrm{ml})$ treatment showed 
approximately $50 \%$ reduction in ERK $1 / 2$ phosphorylation compared to controls. A scrambled dsRNA did not cause a decrease in PDGFR $\beta$ expression (data not shown), nor did it suppress ERK1/2 phosphorylation (Figure 2A). These results demonstrate that PDGFR $\beta$ may be involved in DRD4-mediated ERK1/2 activation.

We then tried to examine the existence of PDGFR $\beta$ specific ligand PDGF-B in the $\mathrm{CHO}-\mathrm{K} 1$ cells. Previous reports have shown that $\mathrm{HB}-\mathrm{EGF}$ acts as a paracrine factor in the GPCR-induced transactivation of EGFR [24]. In addition, the PDGF-C and PDGF-D isoforms are secreted as latent pro-peptides and can be cleaved to their active states by extracellular proteases. This has led to the speculation that either PDGF or a PDGF-like ligand may mediate GPCR-induced PDGFR $\beta$ transactivation via a similar metalloproteinase-dependent process. Thus, to explore any involvement of a paracrine factor in DRD4-mediated PDGFR $\beta$ transactivation, we examined the endogenous expression of PDGFs and PDGFRs in CHO-K1 cells using RT-PCR. As a positive control, the primers were tested in hamster and mouse cardiac tissues and were found to produce PCR products of the expected size (Figure 3Ai, iv, vi). Using the same primers, $\mathrm{CHO}-\mathrm{K} 1$ cells were found to express PDGF-A and PDGF-C; however, no PDGF-B mRNA was detected in these cells (Figure 3Aii). The PCR products obtained for PDGF-D, using two independent primer sets, did not correspond to that obtained with the control hamster tissues (Figure 3Aiii, and data not shown), suggesting that the band from the CHO-K1 cells was due to non-specific amplification. Sequence analysis confirmed that the observed PDGF-D band was due to non-specific amplification of the presenilin gene. Therefore, CHO-K1 cells express only PDGF-A and PDGF-C, and not PDGF-B or PDGF-D. PDGF-A and PDGF-C are PDGFR $\alpha$-specific ligands and have been shown to bind PDGFR $\beta$ only when PDGFR $\alpha$ is also present $[1,25]$. Using RT-PCR, it was found that CHO-K1 cells do not express PDGFR $\alpha$, but do express PDGFR $\beta$ (Figure 3Av). These results suggest that in $\mathrm{CHO}-\mathrm{K} 1$ cells, the transactivation of PDGFR $\beta$ by DRD4 stimulation is unlikely to be produced via a paracrine mechanism by known PDGFR $\beta$ ligands.

The metalloproteinase inhibitor GM6001 is known to block LPA-mediated Shc phosphorylation in COS-7 cells [12]. Thus, we tested the potential role of metalloproteinases in DRD4-mediated ERK1/2 phosphorylation. As shown in Figure 3A, both GM6001 and the mutant of diphtheria toxin CRM197, which binds HB-EGF and inhibits ectodomain shedding [12], reduced the LPAinduced Shc phosphorylation in COS-7 cells. However, they were ineffective in blocking DRD4-mediated ERK1/ 2 phosphorylation in CHO/DRD4 cells (Figure 3B). These results suggest there is little or no role of metalloproteinases in DRD4-mediated ERK1/2 phosphorylation.

Although the RT-PCR experiments showed the absence of PDGFR $\beta$-specific ligands, we sought to exclude the possible activation of PDGFR $\beta$ by a yet undiscovered ligand. To identify any potential PDGFR $\beta$ ligand released upon dopamine stimulation, a co-culture strategy $[12,26]$ in which two different populations of cells were cultured together was employed. We created one population of $\mathrm{CHO}-\mathrm{K} 1$ cells $(\mathrm{CHO} / \mathrm{PR})$, which stably expressed FLAG-tagged human PDGFR $\beta$, but not DRD4. The CHO/DRD4 cell line described above was used as our second population of cells. As expected, when cultured alone, the $\mathrm{CHO} / \mathrm{PR}$ cells showed ERK1/2 activation in response to PDGF-BB, but not to dopamine, while the $\mathrm{CHO} / \mathrm{DRD} 4$ cells responded to both dopamine and PDGF-BB (Figure 3C, left hand side) when cultured alone. Interestingly, when the two cell populations were co-cultured at a high density in a 1:1 ratio, dopamine-induced ERK1/2 phosphorylation was approximately half as that observed with the $\mathrm{CHO} /$ DRD4 monoculture, unlike the PDGF-BB-mediated ERK1/2 response, which was similar in the monocultures and co-culture. We speculated that the reduced dopamine-mediated ERK1/2 phosphorylation in the coculture is due to the decrease of paracrine mediator, as only half of the cells in this culture express DRD4. Furthermore, immunoprecipitation of the FLAG-tagged PDGFR $\beta$ in the $\mathrm{CHO} / \mathrm{PR}$ cells from the co-culture, followed by immunoblotting of phospho-tyrosine residues revealed an enhanced phosphorylation in response to PDGF-BB, but not dopamine (Figure 3C, right hand side). This further suggests that a paracrine mediator of PDGFR $\beta$ activation is not released by the CHO/DRD4 cells within the co-culture, in response to dopamine. Taken together, our results from the co-culture and metalloproteinase inhibitor studies suggest that the mechanism of DRD4-mediated transactivation of PDGFR $\beta$ does not involve a paracrine factor or it involves a paracrine factor that does not induce transactivation.

The observations that PDGF is not involved in DRD4mediated PDGFR $\beta$ transactivation led us to speculate that the DRD4-ERK1/2 pathway is mechanistically different from the growth factor-activated ERK1/2 pathway, although both pathways utilize PDGFR $\beta$. First, we explored the role of PDGFR $\beta$ cross-phosphorylation in DRD4- or PDGF-BB-induced ERK1/2 and PDGFR $\beta$ phosphorylation. A mouse PDGFR $\beta$ mutant with a deletion in the intracellular domain has previously been shown to inhibit PDGF-mediated signaling due to its ability to heterodimerize with the full-length receptor, thereby blocking the formation of functional PDGFR $\beta$ dimers and consequently receptor cross-phosphorylation 


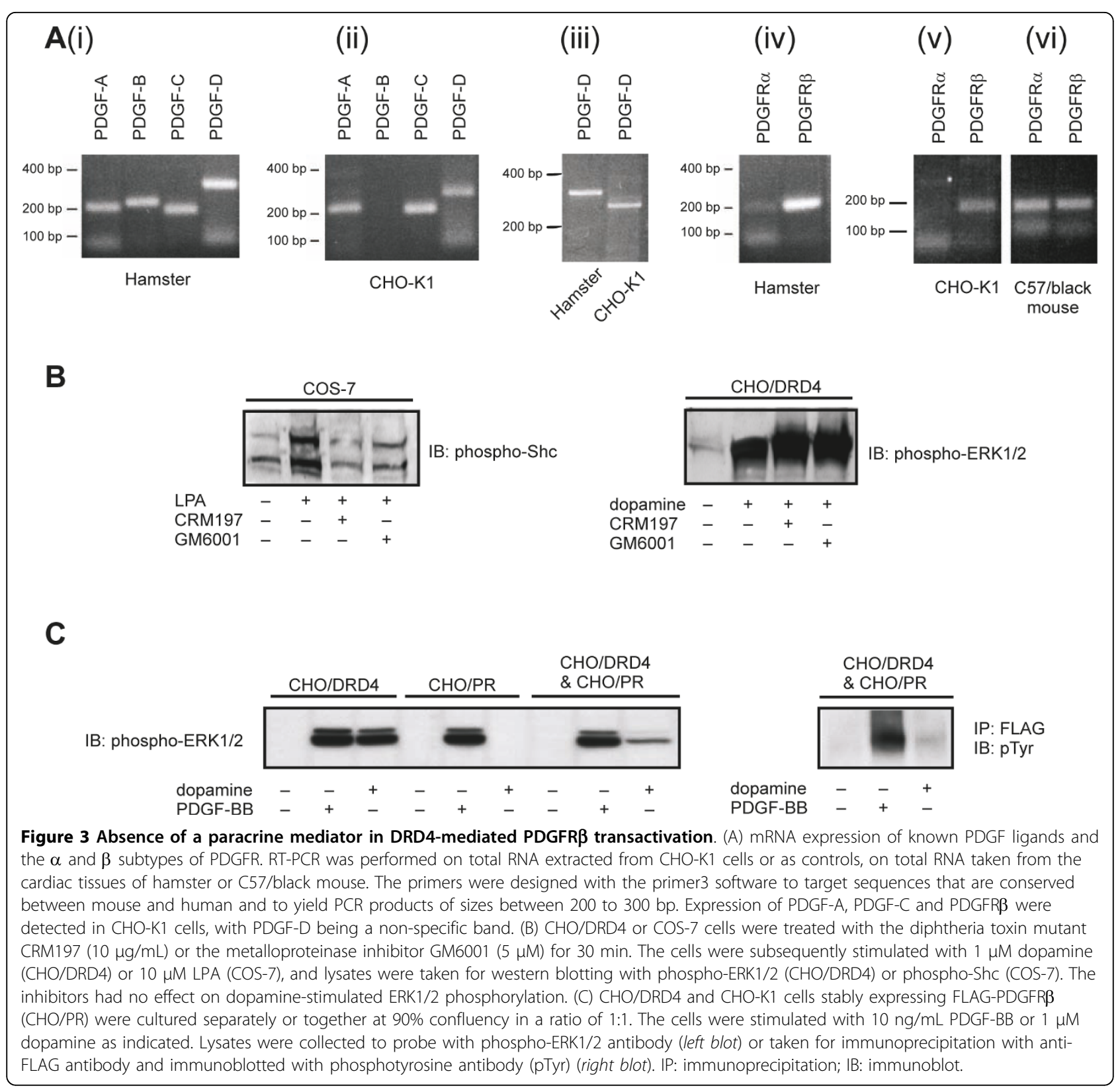

[15]. A similar deletion mutant (see Methods) was created for the human PDGFR $\beta$ (C-truncPDGFR $\beta$ ) and transfected into $\mathrm{CHO} / \mathrm{DRD} 4-\mathrm{PR}$. The cells were lysed and the phosphorylation of ERK1/2 was examined by western blotting with phospho-ERK1/2 antibody (E10). The degree of phosphorylation was quantified using ImageQuant and expressed as percentage of maximal response. The $E C_{50}$ values were determined by fitting to a sigmoidal dose-response equation in GraphPad Prism. The $\log E C_{50}$ values for dopamine were: CHO/DRD4, $-8.56 \pm 0.11(n=4) ; \mathrm{CHO} / \mathrm{DRD} 4-\mathrm{PR},-8.44 \pm 0.23(n=$ $3)$. The $\log E C_{50}$ values for PDGF-BB were: $\mathrm{CHO} /$ DRD4, $-10.13 \pm 0.16(n=4) ; \mathrm{CHO} / \mathrm{DRD} 4-\mathrm{PR},-10.41 \pm$ $0.15(n=3)$. Assays were carried out at or near $\mathrm{EC}_{50}$ concentrations of dopamine and PDGF-BB so that a false negative inhibition due to over-stimulation of the signaling pathway could be avoided (Figure 4A).

The effect of C-truncPDGFR $\beta$ was examined by western blotting with general phospho-tyrosine or site-specific phospho-antibodies as indicated. To prevent the effect from being masked by signal amplification, the cells were stimulated with submaximal concentrations of either PDGF-BB or dopamine. Immunoprecipitation with antiFLAG antibody was performed prior to blotting with general phospho-tyrosine antibodies. Relative to the lac $Z$ control plasmid, transfection of $C$-truncPDGFR $\beta$ reduced 
A
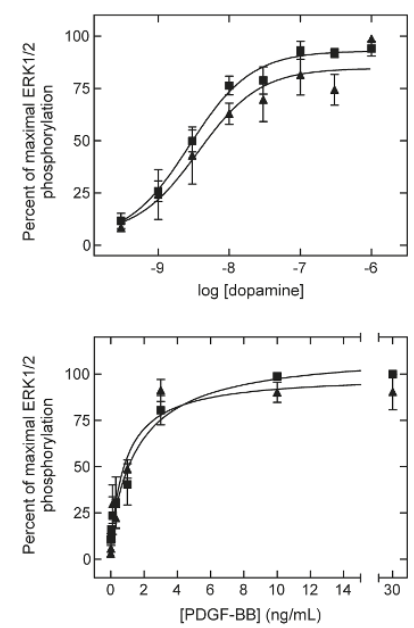

C CHO/DRD4

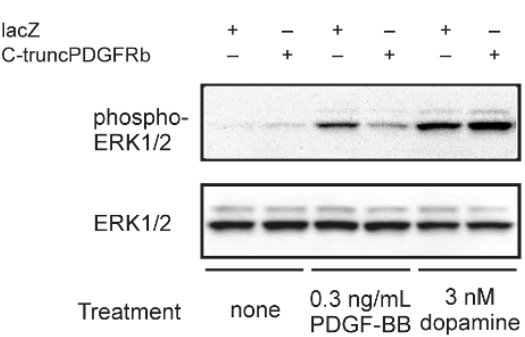

D CHO/DRD4

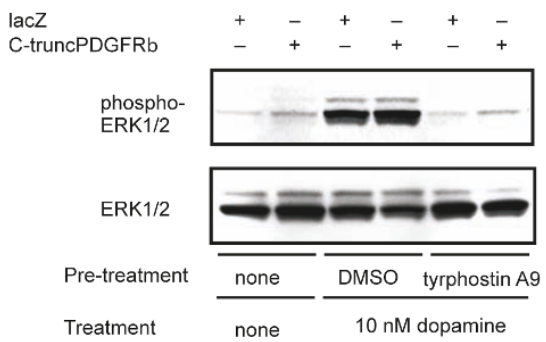

B CHO/DRD4-PR

lacZ

C-truncPDGFRb

IP: FLAG

IB: $p$ Tyr

IP: PDGFRb

IB: PDGFRb

IB: PDGFRb-

pY716

IB: PDGFRbpY1021

IB: phospho-

ERK1/2

IB: ERK1/2
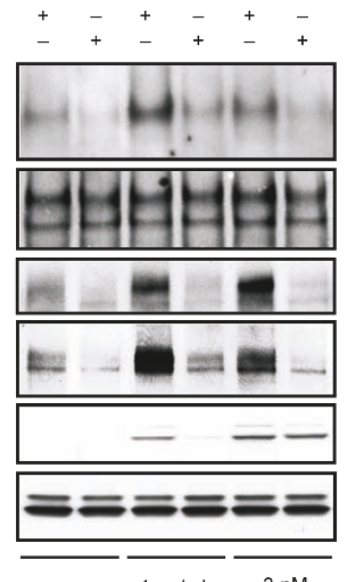

Treatment none $1 \mathrm{ng} / \mathrm{mL} \quad 3 \mathrm{nM}$
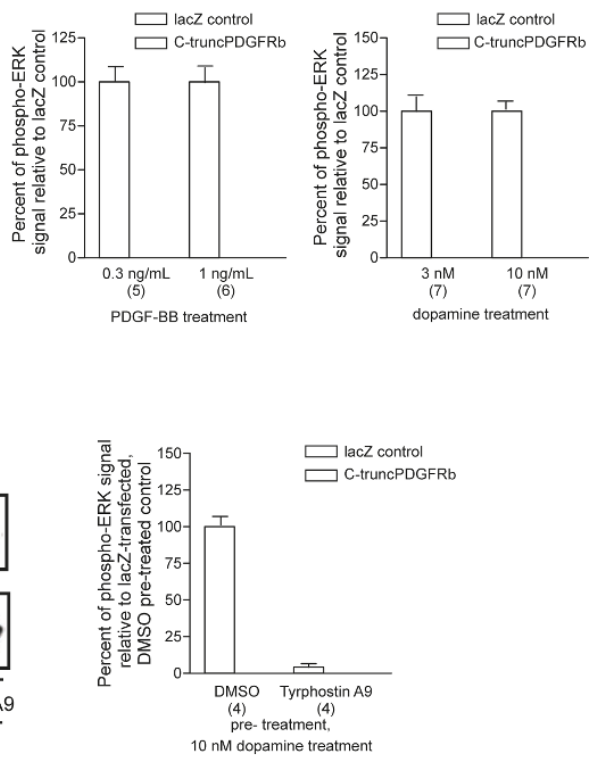

Figure 4 Cross-tyrosine phosphorylation of PDGFR $\beta$ is not required for DRD4-mediated ERK1/2 activation. (A) Dose-response of DRD4and PDGF-BB-mediated ERK1/2 phosphorylation. CHO/DRD4 (black square) or CHO/DRD4-PR (black triangle) cells were treated with different concentrations of dopamine or PDGF-BB for $5 \mathrm{~min}$. (B) Effect of C-truncPDGFR $\beta$ on the phosphorylation of full-length PDGFR $\beta$ and ERK1/2 in CHO/DRD4-PR cells mediated by PDGF-BB and DRD4. CHO/DRD4-PR cells were transfected with C-truncPDGFR $\beta$, or with lacZ as a control. IP: immunoprecipitation; IB: immunoblot. (C) DRD4-mediated phosphorylation of ERK1/2 in CHO/DRD4 was not blocked by C-truncPDGFRß. (D) Requirement for PDGFR $\beta$ in the DRD4-mediated phosphorylation of ERK1/2 in C-truncPDGFR $\beta$-transfected cells. Upper blot shows the phosphorylation of ERK1/2 in lacZ-transfected and C-truncPDGFR $\beta$-transfected CHO/DRD4 cells that have been pre-treated with DMSO or $1 \mu \mathrm{M}$ tyrphostin A9 prior to stimulation with dopamine. (B-D) The blots were stripped and re-probed with antibodies for PDGFR $\beta$ or ERK1/2 to verify that the total protein did not vary between lanes. In (C) and (D), the bar graphs show densitometric measurements of the phosphorylation signal from the respective experiments. The results are expressed as percentages relative to lacZ control and indicated as mean \pm SEM. The number of experiments is indicated in parentheses.

basal PDGFR $\beta$ general tyrosine phosphorylation, as well as receptor phosphorylation in response to both PDGF$\mathrm{BB}$ and dopamine (Figure 4B). A corresponding reduction was also observed at two of the $\mathrm{SH} 2$ domain-binding sites. The phosphorylation of the Grb2 site (Tyr716) and the major PLC- $\gamma$ binding site (Tyr1021) in unstimulated $\mathrm{CHO} / \mathrm{DRD} 4-\mathrm{PR}$ and those stimulated by either PDGF$\mathrm{BB}$ or DRD4 activation was reduced by the CtruncPDGFR $\beta$ to near basal levels (Figure 4B). Similar to its effect on PDGF-stimulated PDGFR $\beta$ tyrosine 
phosphorylation, the C-truncPDGFR $\beta$ also blocked ERK1/2 phosphorylation in response to PDGF-BB. In contrast, the DRD4-mediated ERK1/2 phosphorylation was unaffected by expression of C-truncPDGFR $\beta$. These results suggest that unlike PDGF-mediated signaling, DRD4-induced ERK1/2 phosphorylation is not contingent on PDGFR $\beta$ cross-phosphorylation.

We further confirmed that the differential effect of the C-truncPDGFR $\beta$ on PDGF- and DRD4-mediated signaling was not due to signal amplification caused by our overexpression of recombinant PDGFR $\beta$ by examining ERK1/2 phosphorylation in CHO/DRD4 cells, which express the PDGFR $\beta$ endogenously. Consistent with our observations in CHO/DRD4-PR cells, the CtruncPDGFR $\beta$ blocked PDGF-BB-mediated ERK1/2 phosphorylation in CHO/DRD4 cells (Figure 4C). In contrast, C-truncPDGFR $\beta$ did not inhibit the ERK1/2 phosphorylation that was stimulated by submaximal concentrations of dopamine. To ascertain that the lack of effect of C-truncPDGFR $\beta$ on DRD4-mediated ERK1/2 phosphorylation is not due to overexpression of PDGFR $\beta$, the experiment was also performed in $\mathrm{CHO} /$ DRD4. The $p$ values for the $0.3 \mathrm{ng} / \mathrm{mL}$ and $1 \mathrm{ng} / \mathrm{mL}$ PDGF-BB-treated groups are 0.02 and 0.01 , respectively, according to the paired t-test. Moreover, in the presence of C-truncPDGFR $\beta$, the DRD4-mediated ERK1/2 phosphorylation remained sensitive to PDGFR kinase inhibition, showing that basal kinase activity of PDGFR $\beta$ is still required for DRD4-mediated PDGFR $\beta$ transactivation (Figure 4D).

The lack of the need for PDGFR $\beta$ cross-phosphorylation in DRD4-mediated ERK1/2 activation suggests that PDGFR $\beta$ dimerization is also not required. We investigated the need for receptor dimerization, by utilizing a glutathione $S$-transferase fusion protein to inhibit the formation of PDGFR $\beta$ dimers. Previous reports have shown that a glutathione $S$-transferase-PDGFR $\alpha$-Ig 4 domain fusion protein (GST-Ig4 $\alpha$ ) perturbs PDGFR $\alpha$ dimerization [18]. The extracellular Ig4 domain of PDGFR $\beta$ is known to provide the interface for subunitsubunit interaction without playing a role in ligand binding $[17,18,27,28]$. Therefore, to specifically block PDGFR $\beta$ dimerization, a glutathione $S$-transferasePDGFR $\beta$-Ig4 (GST-Ig4 $\beta$ ) fusion protein was constructed. Pre-incubation of CHO/DRD4-PR cells with GST alone had little effect on the ability of dopamine or PDGF-BB to elicit an ERK1/2 response (Figure 5). However, incubation with GST-Ig4 $\beta$ prevented PDGF-BB-stimulated ERK1/2 phosphorylation. Conversely, blocking PDGFR $\beta$ dimerization with GST-Ig4 $\beta$ did not affect DRD4-mediated ERK1/2 phosphorylation. These results suggest that DRD4 can activate ERK1/2 by utilizing the PDGFR $\beta$ in a way that does not require receptor dimerization.
Previous data from our laboratory [5] suggested the involvement of PI3-kinase in the DRD4-mediated activation of PDGFR $\beta$. In order to determine whether PI3kinase plays a role in the DRD4-stimulated activation of ERK1/2 following the block of PDGFR $\beta$ dimerization, $\mathrm{CHO} / \mathrm{DRD} 4-\mathrm{PR}$ cells were pre-treated with $100 \mathrm{nM}$ wortmannin for one hour prior to incubation with GST or GST-Ig4 $\beta$ and subsequent treatment with dopamine or PDGF-BB. Wortmannin inhibited the DRD4mediated ERK1/2 activation observed following PDGFR $\beta$ dimerization block with GST-Ig4 $\beta$, suggesting a role for PI3-kinase in this pathway.

\section{Discussion}

The present study has demonstrated a novel mechanism for PDGFR $\beta$ signaling, in which DRD4-mediated transactivation of PDGFR $\beta$ and the subsequent activation of ERK1/2 does not involve mechanisms that are characteristic of RTK activation. This new scheme breaks away from the prototypical model, where GPCR-mediated RTK transactivation is ligand-dependent, and so occurs similarly to classical RTK signaling involving receptor dimerization and cross-phosphorylation.

The use of RT-PCR failed to detect any of the known endogenous PDGFR $\beta$ ligands within our $\mathrm{CHO}-\mathrm{K} 1$ cells (Figure 3A). Additionally, inhibition of metalloproteinases failed to suppress DRD4-mediated ERK1/2 activation (Figure 3B), and no evidence of a paracrine mediator was found in DRD4-PDGFR $\beta$ transactivation, as demonstrated by our co-culture experiments (Figure 3C). Furthermore, phosphorylation of Tyr857 of the PDGFR $\beta$, a hallmark of ligand-induced activation, was not seen after dopamine treatment (Figure 1A). These lines of evidence argue strongly against the involvement of a paracrine-mediated event in the DRD4-PDGFR $\beta$ ERK1/2 pathway.

Furthermore, dimerization and subsequent cross-phosphorylation of PDGFR are also not required for DRD4mediated transactivation. DRD4 stimulation led to increased general tyrosine phosphorylation of the PDGFR $\beta$ (Figure 1). However, inhibition of the PDGFR $\beta$ cross-tyrosine phosphorylation with the C-truncPDGFR $\beta$ did not affect dopamine-induced ERK1/2 activation (Figure 4). Similarly, blocking PDGFR $\beta$ dimerization with a GST-Ig $4 \beta$ fusion protein did not diminish DRD4mediated ERK1/2 phosphorylation (Figure 5). Both lines of evidence point to a mechanism that does not require either dimerization or cross-phosphorylation which are hallmarks of RTK activation. Interestingly, wortmannin inhibits the DRD4-mediated ERK1/2 activation observed following PDGFR $\beta$ dimerization block with GST-Ig4 $\beta$ (Figure 5B), suggesting a role for PI3-kinase in this pathway. 

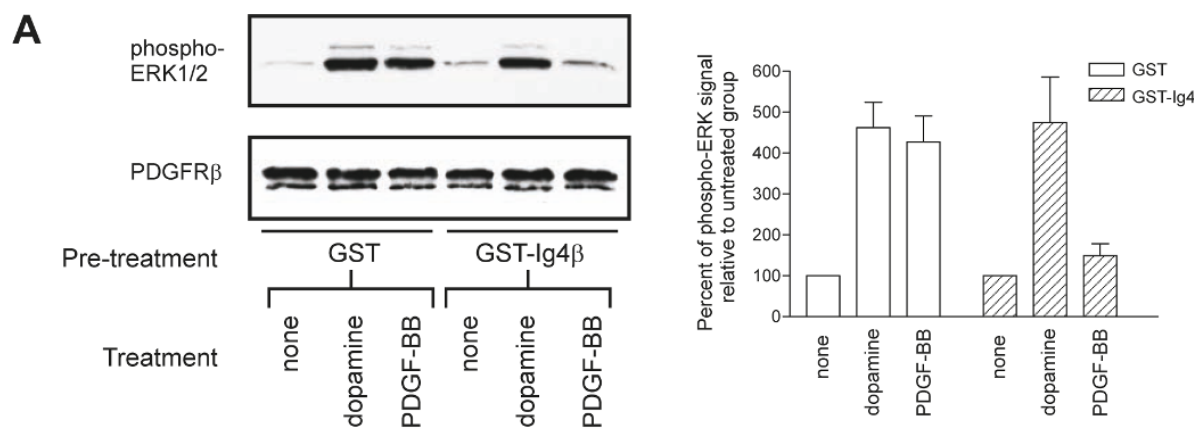

B
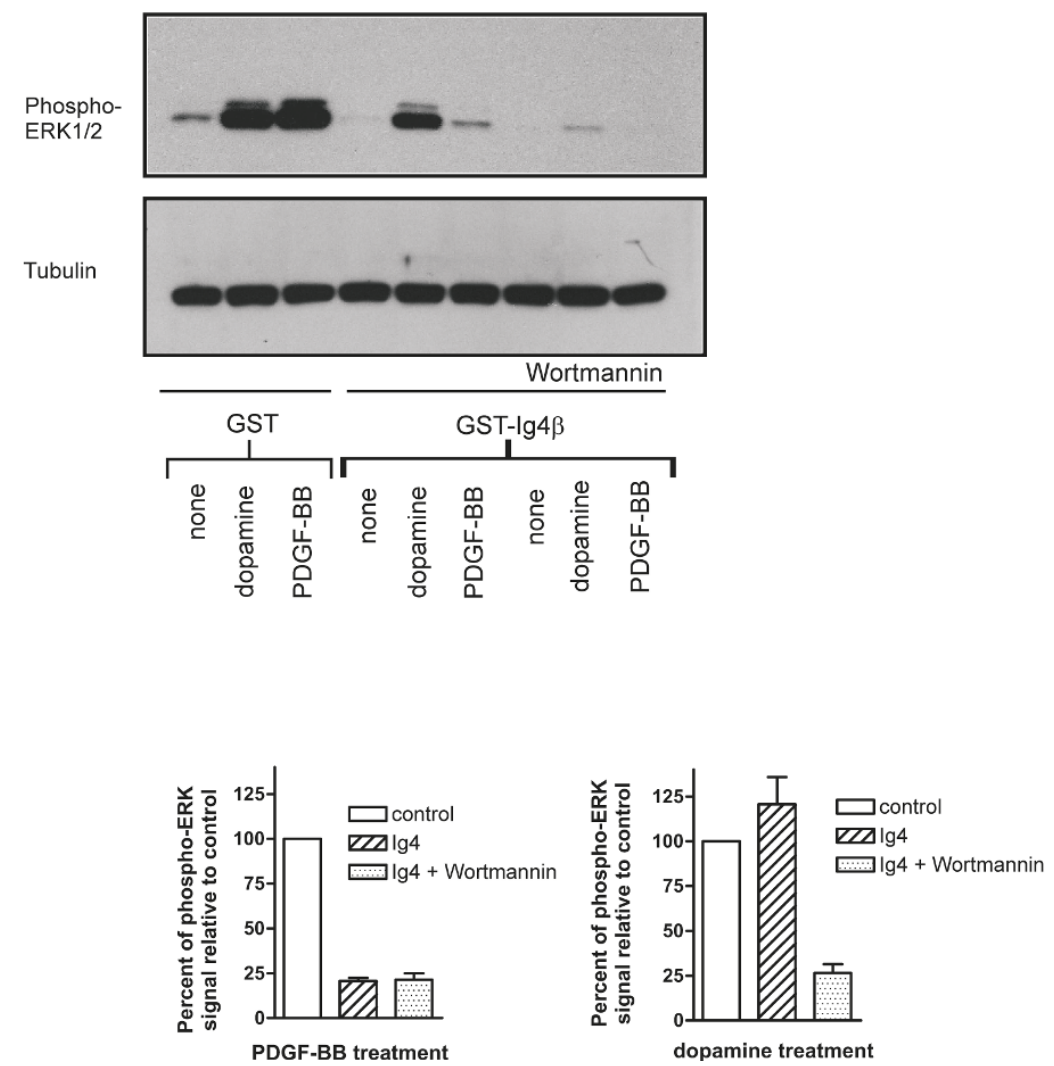

Figure 5 Blocking PDGFR $\beta$ dimerization inhibits ERK1/2 activation in PDGF-BB-treated, but not in dopamine-stimulated CHO-K1 cells. (A) CHO/DRD4-PR cells were pretreated with $4 \mu \mathrm{g} / \mathrm{mL}$ of either GST or GST-PDGFR $\beta$ immunoglobulin domain 4 (GST-Ig4 $\beta$ ) fusion proteins for 20 min at $37^{\circ} \mathrm{C}$ to prevent PDGFR $\beta$ dimerization and were then stimulated with $1 \mu \mathrm{M}$ dopamine or $10 \mathrm{ng} / \mathrm{mL}$ PDGF-BB for 5 min. Lysates were taken for western blotting with phospho-ERK1/2 antibody (upper blot). The same blot was stripped and reprobed for total PDGFR $\beta$ to demonstrate equal loading of all lanes (lower blot). (B) Pre-treatment with $100 \mathrm{nM}$ wortmannin for one hour abolished the dopamine-mediated ERK1/2 signal following PDGFR $\beta$ dimerization block with GST-Ig4 $\beta$. The same blot was stripped and reprobed for $\beta$-tubulin to demonstrate equal loading of all lanes (lower blot). The bar graphs show the densitometric measurement of the relative signals from phospho-ERK1/2 over two to four experiments, and the quantities were given as mean \pm SEM.

In the context of transactivation, the PDGFR $\beta$ tyrosine phosphorylation that follows DRD4 stimulation appears to be unrelated to the ERK1/2 signaling pathway. It is not clear how the transactivated PDGFR $\beta$ mediates signaling in the absence of enhanced tyrosine phosphorylation. The sensitivity of DRD4-mediated ERK1/2 signaling to PDGFR $\beta$ kinase inhibitors suggests that a certain level of basal kinase activity is required. An alternative explanation is that through a tyrosine phosphorylation-independent conformational change, 
the PDGFR $\beta$ may act as a scaffold to mediate DRD4PDGFR $\beta$-ERK $1 / 2$ signaling. In fact, growth factor-activated PDGFR $\beta$ is known to undergo conformational changes that can be either enhanced by mutations that result in constitutive activity [29] or those that suppress kinase activity [30]. Interestingly, several studies have revealed a mechanistic intricacy of PDGFR $\beta$ signaling beyond a simple relationship of dimerization and crossphosphorylation. There is evidence that PDGF-activated mitogenic responses and receptor tyrosine phosphorylation do not always correlate [31-33].

The present study shows that unlike the prototypical mechanism underlying GPCR-RTK transactivation, DRD4-PDGFR $\beta$-ERK1/2 signaling does not involve a paracrine component, nor does it require PDGFR $\beta$ cross-phosphorylation and dimerization. This suggests that PDGFR $\beta$ can act as a monomeric scaffold to transmit DRD4mediated signals, in a tyrosine phosphorylation-independent manner. We have recently demonstrated that DRD4 is able to transactivate immaturely glycosylated PDGFR $\beta$, which is intracellularly localized [34]. These findings preclude the involvement of an extracellular ligand-mediated mechanism of PDGFR $\beta$ activation, and would allow DRD4 to remain engaged in the ERK1/2 signaling pathway, despite desensitization of plasma membrane-expressed PDGFR $\beta$. The actual mechanism of how DRD4 stimulation induces PDGFR $\beta$ transactivation is still unknown, but we speculate that it involves a diffusable factor, such as PI3-kinase, that would be able to act on a monomeric, intracellularly localized PDGFR $\beta$. The DRD4-PDGFR $\beta$ ERK1/2 pathway is distinct from other known forms of transactivation, and so represents a novel system that already has implications in the regulation of downstream effectors such as the NMDA receptor.

\section{Acknowledgements}

The authors would like to express their deepest gratitude to their late mentor and colleague, Professor Hubert Van Tol. This study was supported by the Canadian Institute of Health Research (Grant\# MT-14573). HHMVT was a holder of a Canada Research Chair in Neurobiology. CSS was supported by a postdoctoral fellowship from the Ontario Mental Health Foundation, Canada. MSH was supported by a postgraduate scholarship from the Natural Sciences and Engineering Research Council of Canada.

We gratefully acknowledge Dr. Stephen Ferguson for critical discussion and comments. We are grateful for the FLAG-PDGFR $\beta$ and FLAG-PDGFR 3 K634R constructs provided by Dr. N. J. Freedman (Duke University, NC, USA). We thank colleagues in the Van Tol laboratory and Christine Leung for technical assistance. Colleagues in the Van Tol laboratory, especially Dr. Stewart D. Clark, are acknowledged for their suggestions and comments on the manuscript.

\section{Author details}

'Department of Neuroscience, Centre for Addiction and Mental Health, University of Toronto, Toronto, M5T 1R8, Canada. ${ }^{2}$ Department of Pharmacology, University of Toronto, Toronto, M5T 1R8, Canada.

${ }^{3}$ Department of Psychiatry, University of Toronto, Toronto, M5T 1R8, Canada.

\section{Authors' contributions}

CSS did the RT-PCR, dose-response curves, and c-truncated PDGF receptor experiments. SMV carried out the GST fusion protein work. RSG performed the siRNA studies. MSH carried out the immunoprecipitation and Western blotting experiments for PDGF receptor phosphorylation. Both SMV and CSS participated in the experimental design and writing of the manuscript. FL contributed to important discussions and manuscript writing. The project was initially under the supervision of the late Dr. Van Tol who passed away in April 2006. All authors read and approved the final manuscript.

\section{Competing interests}

The authors declare that they have no competing interests.

Received: 19 April 2010 Accepted: 26 July 2010 Published: 26 July 2010

\section{References}

1. Heldin CH, Ostman A, Ronnstrand L: Signal transduction via plateletderived growth factor receptors. Biochim Biophys Acta 1998, 1378:F79-113.

2. Marinissen MJ, Gutkind JS: G-protein-coupled receptors and signaling networks: emerging paradigms. Trends Pharmacol Sci 2001, 22:368-376.

3. Rubio I, Rennert K, Wittig U, Wetzker R: Ras activation in response to lysophosphatidic acid requires a permissive input from the epidermal growth factor receptor. Biochem J 2003, 376:571-576.

4. Eguchi $\mathrm{S}$, Inagami T: Signal transduction of angiotensin II type 1 receptor through receptor tyrosine kinase. Regul Pept 2000, 91:13-20.

5. Nair VD, Sealfon SC: Agonist-specific transactivation of phosphoinositide 3-kinase signaling pathway mediated by the dopamine D2 receptor. $J$ Biol Chem 2003, 278:47053-47061

6. Oak JN, Lavine N, Van Tol HH: Dopamine D(4) and D(2L) Receptor Stimulation of the Mitogen-Activated Protein Kinase Pathway Is Dependent on trans-Activation of the Platelet-Derived Growth Factor Receptor. Mol Pharmacol 2001, 60:92-103.

7. Kim SJ, Kim MY, Lee EJ, Ahn YS, Baik JH: Distinct regulation of internalization and mitogen-activated protein kinase activation by two isoforms of the dopamine D2 receptor. Mol Endocrinol 2004, 18:640-652.

8. Wang C, Buck DC, Yang R, Macey TA, Neve KA: Dopamine D2 receptor stimulation of mitogen-activated protein kinases mediated by cell typedependent transactivation of receptor tyrosine kinases. J Neurochem 2005, 93:899-909.

9. Maudsley S, Pierce KL, Zamah AM, Miller WE, Ahn S, Daaka Y, Lefkowitz RJ, Luttrell LM: The beta(2)-adrenergic receptor mediates extracellular signalregulated kinase activation via assembly of a multi-receptor complex with the epidermal growth factor receptor. J Biol Chem 2000, 275:9572-9580.

10. Tsai W, Morielli AD, Peralta EG: The $\mathrm{m} 1$ muscarinic acetylcholine receptor transactivates the EGF receptor to modulate ion channel activity. EMBO J 1997, 16:4597-4605.

11. Murasawa S, Mori Y, Nozawa Y, Gotoh N, Shibuya M, Masaki H, Maruyama K, Tsutsumi $Y$, Moriguchi $Y$, Shibazaki $Y$, et al: Angiotensin II type 1 receptorinduced extracellular signal-regulated protein kinase activation is mediated by $\mathrm{Ca} 2+/$ calmodulin-dependent transactivation of epidermal growth factor receptor. Circ Res 1998, 82:1338-1348.

12. Prenzel N, Zwick E, Daub H, Leserer M, Abraham R, Wallasch C, Ullrich A EGF receptor transactivation by $\mathrm{G}$-protein-coupled receptors requires metalloproteinase cleavage of proHB-EGF. Nature 1999, 402:884-888.

13. Kotecha SA, Oak JN, Jackson MF, Perez Y, Orser BA, Van Tol HH MacDonald JF: A D2 class dopamine receptor transactivates a receptor tyrosine kinase to inhibit NMDA receptor transmission. Neuron 2002, 35:1111-1122.

14. Freedman NJ, Kim LK, Murray JP, Exum ST, Brian L, Wu JH, Peppel K: Phosphorylation of the platelet-derived growth factor receptor-beta and epidermal growth factor receptor by $\mathrm{G}$ protein-coupled receptor kinase2. Mechanisms for selectivity of desensitization. J Biol Chem 2002, 277:48261-48269.

15. Ueno $\mathrm{H}$, Colbert $\mathrm{H}$, Escobedo JA, Williams LT: Inhibition of PDGF beta receptor signal transduction by coexpression of a truncated receptor. Science 1991, 252:844-848.

16. Gronwald RG, Grant FJ, Haldeman BA, Hart CE, O'Hara PJ, Hagen FS, Ross R, Bowen-Pope DF, Murray MJ: Cloning and expression of a CDNA coding for the human platelet-derived growth factor receptor: evidence for more than one receptor class. Proc Natl Acad Sci USA 1988, 85:3435-3439.

17. Lokker NA, O'Hare JP, Barsoumian A, Tomlinson JE, Ramakrishnan V, Fretto LJ, Giese NA: Functional importance of platelet-derived growth factor (PDGF) receptor extracellular immunoglobulin-like domains. 
Identification of PDGF binding site and neutralizing monoclonal antibodies. J Biol Chem 1997, 272:33037-33044.

18. Omura T, Heldin CH, Ostman A: Immunoglobulin-like domain 4-mediated receptor-receptor interactions contribute to platelet-derived growth factor-induced receptor dimerization. J Biol Chem 1997, 272:12676-12682.

19. Gordon JA: Use of vanadate as protein-phosphotyrosine phosphatase inhibitor. Methods Enzymol 1991, 201:477-482.

20. Klapper A, MacKay B, Resh MD: Rapid high resolution western blotting: from gel to image in a single day. Biotechniques 1992, 12:650-654.

21. Baxter RM, Secrist JP, Vaillancourt RR, Kazlauskas A: Full activation of the platelet-derived growth factor beta-receptor kinase involves multiple events. J Biol Chem 1998, 273:17050-17055.

22. Hart CE, Seifert RA, Ross R, Bowen-Pope DF: Synthesis, phosphorylation, and degradation of multiple forms of the platelet-derived growth factor receptor studied using a monoclonal antibody. J Biol Chem 1987, 262:10780-10785.

23. Keating MT, Williams LT: Processing of the platelet-derived growth factor receptor. Biosynthetic and degradation studies using anti-receptor antibodies. J Biol Chem 1987, 262:7932-7937.

24. Werry TD, Sexton PM, Christopoulos A: "Ins and outs" of seventransmembrane receptor signalling to ERK. Trends Endocrinol Metab 2005, 16:26-33.

25. Gilbertson DG, Duff ME, West JW, Kelly JD, Sheppard PO, Hofstrand PD, Gao Z, Shoemaker K, Bukowski TR, Moore M, et al: Platelet-derived growth factor C (PDGF-C), a novel growth factor that binds to PDGF alpha and beta receptor. J Biol Chem 2001, 276:27406-27414.

26. Pierce KL, Tohgo A, Ahn S, Field ME, Luttrell LM, Lefkowitz RJ: Epidermal growth factor (EGF) receptor-dependent ERK activation by $\mathrm{G}$ proteincoupled receptors: a co-culture system for identifying intermediates upstream and downstream of heparin-binding EGF shedding. I Biol Chem 2001, 276:23155-23160.

27. Heidaran MA, Pierce JH, Jensen RA, Matsui T, Aaronson SA: Chimeric alphaand beta-platelet-derived growth factor (PDGF) receptors define three immunoglobulin-like domains of the alpha-PDGF receptor that determine PDGF-AA binding specificity. J Biol Chem 1990, 265:18741-18744.

28. Yu JC, Mahadevan D, LaRochelle WJ, Pierce JH, Heidaran MA: Structural coincidence of alpha PDGFR epitopes binding to platelet-derived growth factor-AA and a potent neutralizing monoclonal antibody. J Biol Chem 1994, 269:10668-10674.

29. Chiara F, Bishayee S, Heldin CH, Demoulin JB: Autoinhibition of the platelet-derived growth factor beta-receptor tyrosine kinase by its Cterminal tail. J Biol Chem 2004, 279:19732-19738.

30. Keating MT, Escobedo JA, Williams LT: Ligand activation causes a phosphorylation-dependent change in platelet-derived growth factor receptor conformation. J Biol Chem 1988, 263:12805-12808.

31. Kazlauskas A, DiCorleto PE: A comparison of the platelet-derived growth factor-dependent tyrosine kinase activity in sparse and confluent fibroblasts. J Cell Physiol 1986, 126:225-236.

32. Quinones MA, Mundschau LJ, Rake JB, Faller DV: Dissociation of plateletderived growth factor (PDGF) receptor autophosphorylation from other PDGF-mediated second messenger events. J Biol Chem 1991, 266:14055-14063.

33. Cartel NJ, Liu J, Wang J, Post M: PDGF-BB-mediated activation of p42 (MAPK) is independent of PDGF beta-receptor tyrosine phosphorylation. Am J Physiol Lung Cell Mol Physiol 2001, 281:L786-L798.

34. Gill RS, Hsiung MS, Sum CS, Lavine N, Clark SD, Van Tol HH: The dopamine D4 receptor activates intracellular platelet-derived growth factor receptor beta to stimulate ERK1/2. Cell Signal 2010, 22:285-290.

doi:10.1186/1756-6606-3-22

Cite this article as: Chi et al:: Transactivation of PDGFR $\beta$ by dopamine D4 receptor does not require PDGFRß dimerization. Molecular Brain 2010 3:22.

\section{Submit your next manuscript to BioMed Central and take full advantage of:}

- Convenient online submission

- Thorough peer review

- No space constraints or color figure charges

- Immediate publication on acceptance

- Inclusion in PubMed, CAS, Scopus and Google Scholar

- Research which is freely available for redistribution 